\section{Faecal incontinence in women}

\author{
Prof (Dr) Hemkanta Sarma
}

It was way back in 1894 when Sir Howard Kelly performed bilateral iliac artery ligation to control intraoperative pelvic haemorrhage for cervical cancer for the first time. It had not been used extensively in the appropriate moment ${ }^{1}$. Faecal incontinence is a subject not frequently talked about amongst the medical fraternity. But it is a socially and psychologically devastating condition for both the patients and their families. Faecal incontinence is defined as the involuntary loss of stool at any time of life after toilet training ${ }^{1}$. Nelson and co authors in Wisconsin, in a community based study found a prevalence of significant faecal incontinence in $2.2 \%$ cases, where $63 \%$ of the affected population were female ${ }^{2}$. Perry et al found $1.4 \%$ prevalence with no gender preference ${ }^{3}$.

Types - Anal incontinence and faecal incontinence terms are often used, but these are not synonymous. According to the International Urogynaecology Association (IUGA) and International Continence Society (ICS), anal incontinence is involuntary loss of faeces. Urge incontinence is one where the individual feels the sensation but cannot control; on the other hand passive incontinence is one where the person does not feel any sensation or urge, only passes spontaneously without effort.

Risk factors and causes - Advancing age, obstetrical trauma, pelvic surgery, chronic diarrhoea, obesity, chronic constipation and neuromuscular disorders are commonly attributed as causative factors for faecal incontinence ${ }^{4}$. Risk factors are as follows: age and functional dependency, cognitive impairment, limitation in daily

\author{
Correspondence: \\ Prof (Dr) Hemkanta Sarma, \\ Professor \& HOD, Department \\ of Obstetrics and Gynaecology, \\ Jorhat Medical College, Jorhat, \\ Assam, India; Email - \\ sarmahemkanta@gmail.com
}

Distributed under Creative Commons Attribution-Share Alike 4.0 International.

activities, prolonged hospitalization in nursing home, stroke, diabetes, obesity, poor general health, high parity, vaginal prolapse etc.

Pathogenesis - Faecal incontinence in women has different pathogenesis as follows: 1) Rectovaginal fistula (RVF) - rarely congenital due to improper development of cloaca; more commonly, following obstetrical trauma or gynaecological surgery. 2) "Multiple hit hypothesis" can explain the usual cases of faecal incontinence where the obstetric anal sphincter injury (OASIS) acts as the "initial hit", is compounded by other factors such as pelvic laxity resulting from pudendal neuropathy and menopause, in addition to ageing ${ }^{5} .3$ ) Rectum which acts as a reservoir, internal sphincter which acts as a gate under autonomic control and the external sphincter acting as a gate under self control - sometime goes out of order leading to faecal incontinence.

Management - There are several treatment options. Many patients will respond to non surgical methods which are considered to be the first option. Of course in selected cases and in case of failed conservative management, permanent surgical methods are to be used.

1) Behavioral techniques: Healthy life style habits, diet modification, bowel retraining, pelvic muscle exercises.

2) Medications: Drugs controlling bowel movement disorder.

3) Sacral neuromodulation: A small implanted neurostimulator is used to send mild electrical pulses to the sacral nerve to reduce symptoms.

4) Permanent surgical procedure: Direct sphincter repair with an overlapping sphincteroplasty. 
5) In case of recto-vaginal fistula repair of the fistula is necessary; in difficult and high fistula a colostomy should be done prior to repair.

6) Other new methods are biofeedback, Procon incontinence device, local injection of synthetic materials, radiofrequency energy (secca procedure), antegrade colonic enemas, sphyncteroplasty, gluteoplasty, graciloplasty - both stimulated and nonstimulated, artificial bowel sphincter and sacral nerve stimulation.

Prevention - Preventive strategies for faecal incontinence includes: avoiding diarrhoeal triggers, discouraging routine episiotomies, early recognition and management of obstetric injuries.

Besides all these, the risk factors as mentioned above are to be taken care of at the earliest possible moment ${ }^{6}$. As per cochrane review ${ }^{5}$, caesarean delivery has no advantage over vaginal delivery in prevention of faecal incontinence. Of course, in case of previous history of faecal incontinence, sphincter injury or successful repair of RVF caesarean delivery is recommended.

Conclusion - Extensive studies regarding faecal incontinence is necessary both in the community and institutional level. Awareness amongst the common population about the risk factors and treatment options is necessary. Orientation and updating of knowledge regarding preventive strategies and treatment options amongst the medical community is also essential. With increasing life expectancy, advancing health care system we are getting increasing number of faecal incontinence cases day by day. But with continuing efforts of increasing awareness in the community, continued research on the subject and coordinated approach of concerned specialties will definitely show a vista of light in near future.

Conflict of interest: None.

Disclaimer: Nil.

\section{References}

1.Cooper ZR, Rose S. Fecal incontinence: a clinical approach. Mt Sinai J Med. 2000 Mar; 67(2): 96-105.

2.Nelson R, Norton N, Cautley E, Furner S. Community based prevalence of anal incontinence. JAMA. 1995; 274(7): 559-61.

3.Perry S, Shaw C, McGrother C, Matthews RJ, Assassa RP, Dallosso $\mathrm{H}$, et al. Prevalence of faecal incontinence in adults aged 40 years or more living in the community. GUT. 2002; 50 (4): 480-84.

4.Makol A, Grover M, Whitehead WE. Fecal incontinence in women: causes and treatment. Womens Health (Lond). 2008 Sep; 4(5): 517-28.

5.Meyer I, Richter HE. Impact of faecal incontinence and its treatment on quality of life in women. Womens Health (Lond ). 2015 Mar; 11(2): 225-38.

6.Shamliyan T, Wyman J, Bliss DZ, Kane RL, Wilt TJ. Prevention of urinary and fecal incontinence in adults. Evid Rep Technol Assess (Full Rep). 2007 Dec; 161: 1-379.

\section{Prof (Dr) Hemkanta Sarma ${ }^{1}$}

${ }^{1}$ Professor \& HOD, Department of Obstetrics and Gynaecology, Jorhat Medical College, Jorhat, Assam, India 